\title{
SPUR GEAR DESIGN: SOME NEW PERSPECTIVES
}

\author{
Edward. E. Osakue ${ }^{1}$, Lucky Anetor ${ }^{2}$ \\ ${ }^{I}$ Department of Industrial Technology, Texas Southern University, Houston, Texas, USA \\ ${ }^{2}$ Department of Mechanical Engineering, Nigerian Defence Academy, Kaduna, Nigeria
}

\begin{abstract}
New perspectives such as harmonic mean, contact patch as translating third body, contact form factor, and service load factor are introduced in spur gear design. The harmonic mean rule characterizes the physical and geometric properties of the contact patch. The contact patch is construed as a body in translation during gear teeth engagement. The contact form factor may be used to compare the load capability of different pressure angle standards. The service load factor captures the influence of different conventional rated load modification factors. Gear design analysis is separated into design sizing and design verification tasks. Design sizing and design verification formulas are formulated and presented in simplified forms for the Hertz contact and the Lewis root bending stresses. Three design Examples are presented through which it is demonstrated that results from the contact and root bending stress capacity models compare very favorably with American Gear Manufacturers Association (AGMA) results. The worst differences in the results are 5.23\% for contact stress in design Example 2 and $-6.59 \%$ for root bending stress for design Example 1. In design Example 3, it is shown that using pinion teeth number higher than 17 or 18 can leads to overall size reduction of gearset. This is important because of possible manufacturing cost reduction and higher mesh efficiency. Comparison of proposed approximations for mesh overload, internal overload and service load factors for design sizing and design verification tasks yielded very close results. The highest variance in the three design examples between proposed approximated and AGMA values of these parameters is $-5.32 \%$, indicating a slightly higher or conservative value for design sizing. Due to the very favorable results in comparison with AGMA values, the design approach appears to be an acceptable one in the preliminary design of spur gears because of simplicity and transparency.
\end{abstract}

\section{Keywords: Gears, Design, Contact, Bending, Fatigue, Sizing, Verification}

\section{INTRODUCTION}

A gear is a toothed disk used to transmit power and motion when mounted on a rotating shaft. In most applications, it is made separate from the shaft but it could be made integral with the shaft, especially when small in size. Gear types include spur, single helical, double helical, straight bevel, spiral bevel, hypoid, and worm gears [1]. Specialized gears such as harmonic, non-circular, sector, etc. gears are also available. When gear teeth fit together or interlock, they are said to be in mesh [2]. A gearset is a pair of gears coupled together in a mesh. The smaller gear is generally called a pinion while the larger gear is called "gear" or "wheel". The gear transmitting the force or motion is called the driver and the gear connected to the driver is called the driven gear. When important power drive criteria are smooth, slip-free uniform motion, light weight, high speed, high efficiency, precise timing, and compact design; in nearly all cases; an appropriate system of gears can be selected to meet the needs [3].

Gear tooth profiles providing constant relative velocity or conjugate action are the vogue in gear technology. The involute gear curve is the most common gear tooth profile curve toady and was presumably first suggested by Leonard Euler, a Swiss mathematician. However, Robert Willis, a Cambridge University professor developed the practical involute gear profile curve used in gears today. Charles Camus and Phillipe de Lahire are other early pioneers in toothed gearing technology [4]. Kinematically, a gear pair motion is analogous to that of a pair of two cylinders of equivalent pitch diameters, rolling without slip. However, the motion of two meshing gear teeth consists generally of a combination of rolling and sliding [4]. Today, several standards are used in the gear industry that include International Standardization Organization (ISO), American Gear Manufacturers Association (AGMA), Deutsches Institut fur Normung (DIN) and Japanese Industrial Standards (JIS) but the most popular standards are the ISO and AGMA standards [5]. According to Euro Trans [6], current gear standards of ISO 6336, DIN 3990, and AGMA 2101-D04 are partially equivalent. A gear designer today must remember that the major objective in a gear drive is to transmit higher power with smaller sizes that can be constructed at minimum manufacturing cost, operate reasonably free of noise and vibration with little maintenance [4].

Spur gears have teeth projecting radially and parallel to the axis of the shaft and they have been used since ancient times [2]. When the teeth are on the outside of a disk, the gear is called external spur gear. If the teeth are on the inside face of the disk, the gear is called an internal spur gear. Most applications use external spur gears. Internal spur gears are used sometimes to achieve a short center distance and most often in epicyclic gearing. When the pinion and gear are in mesh, teeth contact occurs on two convex profile curves through which the driver exerts a tangential force on the driven gear at the pitch circle radius. The moment of the tangential force about the shaft centers is the torque 
developed at the shafts. When the gearset thus rotate, power proportional to the torque is transmitted [7].

Spur gears are relatively simple to design, manufacture, check for precision, and are relatively inexpensive. They exert only radial loads on bearings and small variations in center distance can be tolerated. To avoid high frequency vibrations and acceptable noise levels, they are normally used for pitch line speed up to $20 \mathrm{~m} / \mathrm{s}$, but may be used at higher speeds like other gears [3]. Relative sliding motion component varies during engagement, being zero at the pitch circle radius and maximum at the beginning and ending periods of the engagement. The average sliding speed is generally small in spur gear meshes [3].

Gears fail in service like other mechanical elements, for a variety of reasons. Sometimes, rising noise and vibration betray impending gear failure, but often total failure is the only indicator of a problem in a gear train [8, 9]. Several potential failure modes can be associated with gearing depending on gear type, load, speed, manufacturing accuracy, assembly details, bearings, lubrication, shaft characteristics and environmental factors. Of the several potential failure modes in gearing, the two prominent modes of gear failure are surface fatigue or pitting and bending fatigue $[3,10,11]$. Fatigue failure is due to crack formation and propagation induced by repeated loading. A crack normally initiates at a discontinuity where there is a cyclic maximum stress [12]. Various conditions such as residual stress, elevated temperature, temperature cycling, corrosive environment, surface scratches, internal voids, inclusions, high-frequency cycling can accelerate crack initiation. Cracks grow along planes normal to the maximum tensile stress [12] and when the growth becomes unstable, brittle fracture rapidly follow.

Pitting is the appearance of tiny dents or "pits" on gear tooth surface due to repeated high contact stress. At increased gear speed, the prospects for pitting and scoring failure modes in gears increase. The German physicist, Henry Hertz developed expressions for the stresses created when curved frictionless surfaces are loaded in contact in 1881. Thus contact stresses are generally called Hertz stresses and his solution is the basis of pitting failure in gear design. Pitting occurs in gears when the surface durability of the meshing flanks is exceeded, resulting in crack growth followed by particle break out from the flank [10]. It is believed that a shear stress initiated crack beneath the surface due to excessive repeated Hertz contact stresses that gradually develops to the tooth surface and causes shearing away of some materials thus leaving a pit behind. Pitting generally appears first at or below the pitch point on the pinion tooth $[3,4,13]$. In addition to contact stress, pitting is influenced by sliding velocity, lubricant viscosity, and friction [4]. For maximum durability, it is desirable to distribute the wear uniformly amongst all gear teeth [14].

Gear failure in bending fatigue is one of the common modes of failure. In 1892, the Philadelphia Engineers club recognized Wilfred Lewis presentation on this mode of failure [15] which still serves as the basis for bending fatigue design today. The maximum tensile stress occurs at the root radius on the loaded or active side of the gear tooth. However, as speeds increase, so do the prospects for pitting and scoring modes of failure in gears $[13,14]$.

According to Bergseth [10], Finite Element Method (FEM) can be used to conduct more precise analysis of tooth contact stress and of course bending stress. Therefore FEM results can be used to assess acceptability of standard calculations methods. Rameshkumar et al [16] conducted a comparative study of bending and contact stresses of normal contact ratio (NCR) and high contact ratio (HCR) spur gears using FEM. Contact ratio is a measure of the average number of teeth in engagement at the same time during gear operation. NCR gear sets have contact ratio less than 2 and HCR gear sets have contact ratio of 2 and above. They showed that maximum root bending stress occurs slightly above the pitch circle at a point called the highest point of single tooth contact (HPSTC) for the NCR gear set and the first lowest point of double tooth contact (FLPDTC). The maximum contact stress occurred during the period of single tooth contact around the pitch circle for the NCR gear set and that for the HCR gear set occurred at the FLPDTC, also around the pitch circle. This current study is limited to NCR gearset only. A comparative study of ISO and AGMA gear standards by Kawalec et al [5] indicates that predicted bending stress by ISO method are higher than those of AGMA. Pasta and Mariotti [17] used FEM to analyze the contact stress of profile modified spur gears and found that the FEM results were generally lower than ISO predicted values. Bommisetty [15] provided results of Finite Element Analysis (FEA) of a gearset that show that AGMA bending stress deviated from the FEA value by $0.9 \%$ while the contact stress deviated from the FEA value by $0.6 \%$. Karaveer et al [18] reported AGMA contact stress results that deviated from FEM values by $1.29 \%$. These results suggest that AGMA methods are quite accurate in these applications.

The optimal design of a spur gear mesh is a problem of considerable interest in mechanical design [13]. In recent years, gear design has become rather complicated and comprehensive [4]. A comprehensive design of gears is complicated. For instance, an Australian cylindrical gear design standard (AS2938) lists 88 different variables and constants and contains 32 different charts [14]. Generally, AGMA and ISO [10] standards for surface durability calculations are time consuming and it can be difficult. AGMA and ISO gear design approaches seem to be very similar and both approaches apply a series of modification factors to approximate actual load and actual strengths in gear design [19, 20]. Differences in the approaches manifest in the applied modification factors and their evaluation. However, AGMA methods tend to have fewer modification factors and thus simpler in applications. Therefore, AGMA approach was adopted in the present work. This study explores the possibility of bringing some simplifications into spur gear design by reformulating contact and bending fatigue stress formulas for design verification. Also design sizing is considered and strategies are developed for easy implementation. 


\section{CONTACT FATIGUE CAPACITY MODEL}

Pitting is the appearance of tiny pits on gear tooth surface due to particle detachment because of repeated high contact stress. It has been observed that pitting mostly occurs in the vicinity of the pitch line [4]. Pitting at and below the pitch point on the pinion tooth is a common failure mode of gearsets [13]. Prolong operation after pitting begins roughen the gear tooth surface, resulting in deterioration of form [7]. In a speed reducer drive, the pinion is more vulnerable to pitting because it makes more revolutions per unit time. In a speed increaser drive, the gear is more vulnerable to pitting. At increased pitch line speed, the prospects for pitting and scoring failure modes in gears increase. Pitting can be prevented by keeping contact stresses below the contact fatigue strength. For maximum durability, it is desirable to distribute the wear uniformly amongst all gear teeth. The best case would be that a re-meshing of a pinion tooth occurs after it makes a number of revolutions equal to the number of pinion teeth. This can be achieved by providing a hunting tooth. A hunting tooth ensures that the number of teeth on the pinion and gear do not have a common divisor. This means an integer velocity ratio has to be avoided in a gearset transmission. This may be permissible in power transmission gearing where some speed variation can be tolerated. A hunting tooth is undesirable in control gears where precise motion transmission is the main design objective.

During engagement, contact occurs in a gear mesh on two convex surfaces and the contact point would trace out a line if the gear materials and supporting structures were infinitely rigid. Due to material elasticity, the gear teeth deform slightly to form a rectangular contact patch. Kinematically, a gear pair in mesh is analogous to that of a pair of two cylinders of equivalent pitch diameters, rolling without slip. The state of stress created by two cylinders in contact under a normal load was first formulated by Hertz in 1881.

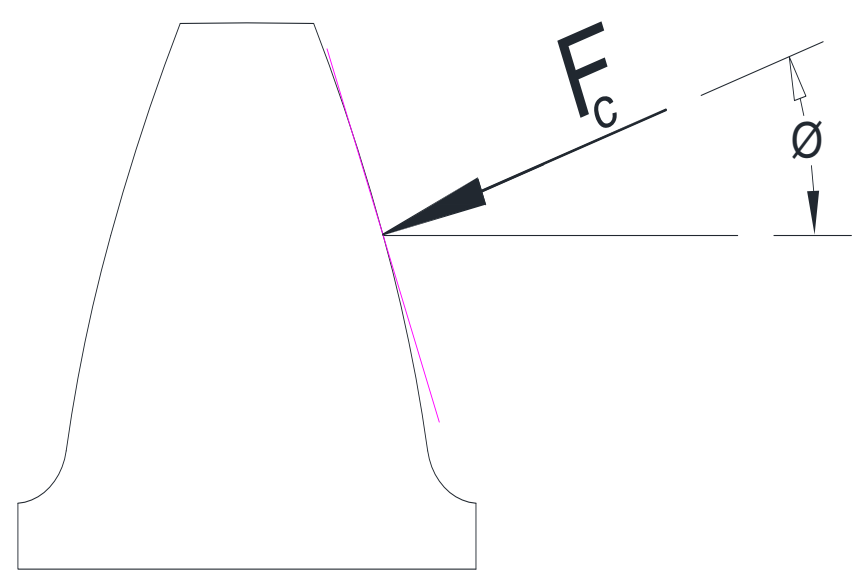

Fig. 1: Contact load on gear tooth

Fig. 1 shows the contact force acting at the pitch point. For two smooth cylinders in contact, the maximum contact or Hertz stress is obtained as [21]:

$$
\begin{aligned}
& \sigma_{H}=\sqrt{\frac{F_{c} E_{c} \times 10^{3}}{\pi b \rho_{c}}} \\
& E_{c}=\frac{2 E_{1} E_{2}}{E_{1}\left(1-v_{2}^{2}\right)+E_{2}\left(1-v_{1}^{2}\right)} \\
& \rho_{c}=\frac{2 \rho_{1} \rho_{2}}{\rho_{1} \pm \rho_{2}} \\
& \rho_{1,2}=0.5 d_{1,2} \sin \phi
\end{aligned}
$$

$E_{1}$ and $E_{2}$ are measured in GPa, in Eq. (2) while $\rho_{1}$ and $\rho_{2}$ are measured in $\mathrm{mm}$ in Eq. (3). The positive operator in the denominator of Eq. (3) is for external gears and the negative operator is for internal gears. Note that the radius of curvature for each gear is evaluated at the pitch point, but need not be. Now $\rho_{c}$ and $E_{c}$ may be interpreted as geometric and material property attributes of a contact patch or zone. From Eqs. (3) and (4), it is observed that these quantities are obtained respectively, as the harmonic mean of the radii and elastic moduli of the contacting cylinders. It is deduced, therefore, that the geometric and material properties of a contact patch in contact fatigue may be estimated using the harmonic mean rule. It may be helpful to consider the contact patch as translating a third body material during gear engagement with its distinct physical properties. The contact stress is that of this third body and pitting occurs on the gear or pinion if the contact stress is higher than the contact fatigue strength of the pinion or gear. For a gear pair in contact:

$$
\begin{aligned}
& F_{c}=\frac{F_{t}}{\cos \phi} \\
& \mu=\frac{d_{2}}{d_{1}}=\frac{z_{2}}{z_{1}}
\end{aligned}
$$

Combing Eq. (3) and Eq. (5):

$\rho_{c}=\frac{d_{2} d_{1}}{d_{2} \pm d_{1}} \sin \phi=\frac{d_{2}}{\mu \pm 1} \sin \phi$

Generally in involute gearing, $\rho_{c}$ is not constant during contact since the contact point is moving throughout the period of engagement. The contact point in a mesh changes from the top of the driving tooth through the pitch circle to the base of the tooth [7]. However, Eq. (6) applies at the pitch point only.

Combing Eq. (1), Eq. (4) and Eq. (6), then: 
$\sigma_{H}=\left[\frac{K_{f} F_{t}(\mu \pm 1) E_{c} \times 10^{3}}{b d_{1}}\right]^{1 / 2}$

where $\sigma_{H}$ is measured in MPa.

The parameter $K_{f}$ is given by:

$$
K_{f}=\frac{2}{\pi \sin 2 \phi}
$$

$K_{f}$ depends on the form of tooth profile and contact area, so it is named the gear form factor. For a gear with $20^{\circ}$ standard pressure angle, the value of $K_{f}$ is evaluated as 0.990. It is assumed to be 1.0 in this study. The parameter $K_{f}$ may be used to assess the relative load capacities of different gear standards. For instance, its value is 0.831 for a $25^{\circ}$ pressure angle gear, which gives a load capacity of $20 \%$ above that of a $20^{\circ}$ pressure angle gear.

For a gearset, when $T_{1}$ or $T_{2}$ is measured in $\mathrm{Nm}$ :

$$
F_{t}=\frac{2 T_{1} \times 10^{3}}{d_{1}}
$$

Substitute Eq. (9) in Eq. (7) to obtain the theoretical contact stress capacity model of:

$$
\sigma_{H}=\left[\frac{2 K_{f}(\mu \pm 1) E_{c} T_{1} \times 10^{6}}{b d_{1} d_{2}}\right]^{1 / 2}
$$

Eq. (10) is the theoretical model for the Hertz contact stress on a spur gear tooth at the pitch point. For practical applications, the expected design load on a gear may be expressed as the rated load multiplied by a service load factor, $K_{s}$. The service load factor is used to account for load increases during normal operations of the gearset. It takes care of load excitations beyond the rated value that are reoccurring in nature and represents a magnification factor for the rated load in a gear design problem. The service load factor in gear design may be estimated by a multiplicative model as:

$$
K_{s}=K_{o} K_{v} K_{m} K_{r} K_{c}
$$

AGMA provides methods for estimating $K_{v}, K_{m}$, and $K_{r}$. In [21], there are discussions on the estimation of $K_{v}, K_{m}, K_{r}$, and a value of 1.1 is suggested for $K_{c}$.
Reference may be made to these works for more information. Therefore Eq. (10) may be rendered as:

$$
\sigma_{H}=10^{3} \times\left[\frac{K_{f} K_{s}(\mu \pm 1) E_{c} T_{1}}{b d_{1} d_{2}}\right]^{1 / 3}
$$

Eq. (12) is explicit and transparent in reflecting the principal design parameters that determine the Hertz contact stress in spur gears. This brings some simplicity in gear design as the "I" parameter in AGMA model is eliminated. AGMA recommends that the contact stress should be evaluated at the lowest point of single tooth contact (LPSTC) because above that point, the load is being shared with other teeth. The AGMA parameter "I" can be computed for LPSTC but is somewhat complicated [7]. The geometric, material property, and rated load parameters of a gearset are concisely expressed in Eq. (12) in a format that is easy to remember.

\section{BENDING FATIGUE CAPACITY MODEL}

Gear failure in bending fatigue is one of the common modes of failure. The bending strength of gear teeth was first calculated to a reasonable degree of accuracy by Wilfred Lewis in 1892 [15, 21]. He modeled a gear tooth as a short cantilever beam on a rigid base with the transmitted load applied near the tip of the gear tooth and considered a maximum parabola inscribed inside the tooth shape. A parabolic shaped cross-sectional beam develops constant bending stress on the surface of the beam. The maximum tensile stress occurs at the root radius on the loaded or active side of the gear tooth as shown in Fig. 2. Depending on the geometry of the gear tooth and the characteristics of loading, the stress concentration at the root radius at the region of maximum tensile stress may vary from 1.4 to 2.5 [22]. In ISO standard, an experimental value of 2.0 is used for the root stress concentration factor [19]. Due to repeated loading of a gear tooth, this region becomes the preferential site for initiation of fatigue crack. Several factors may be attributed to bending fatigue failure and include poor gear design, improper assembly, misalignment of gears, overloads, inadvertent stress raisers or subsurface defects, and use of incorrect materials and heat treatments [23]. If bending fatigue failure mode is the main failure problem, the minimum number of teeth on the pinion that avoids interference will give the strongest gearset [13].

In Fig. 2, the contact force in Fig. 1 has been resolved into a tangential or transmitted force and a radial force. The contact force is assumed to be acting at the highest point of single tooth contact (HPSTC) as recommended by AGMA. Lewis had assumed the load to be acting at the tip of the gear tooth and ignored the radial force component causing compressive stress and the shear stress from the transmitted force. He also did not consider stress concentration which was not understood at that time. Compressive stresses, in general, do not cause fatigue failure because crack growth is due to tensile stress, though shear stress may initiate the growth. In gear design, it is experimentally established that 
the effects of the compressive and shear stresses are marginal, so the tensile bending stress predominantly determines the bending fatigue strength of a gear tooth [4].

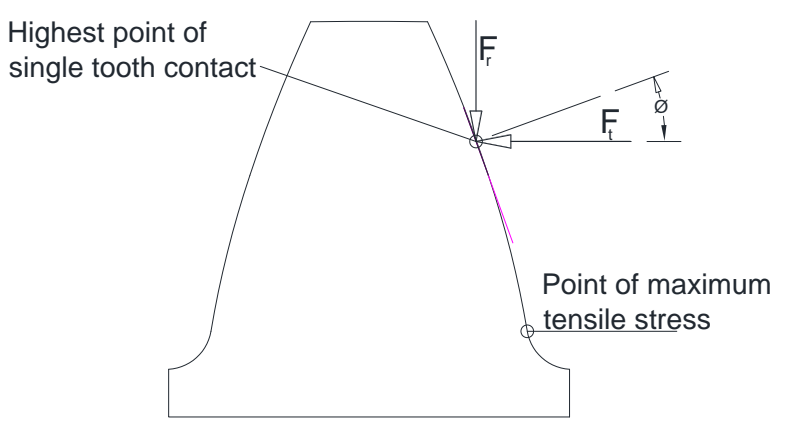

Fig. 2: Gear under bending load

The AGMA gear root bending stress model is a modification of the Lewis model and considers the compressive stress due to the radial load and the influence of stress concentration. Also, the transmitted load is assumed acting at the worst location on the gear tooth for maximum bending stress. In normal contact ratio spur gears, the worst load condition is when one pair of gear teeth is carrying the transmitted force load at the HPSTC [24, 25]. Taking account of the service load factor, $K_{s}$, the AGMA capacity model for the gear root bending stress is:

$$
\sigma_{b}=\frac{2 K_{s} T \times 10^{3}}{d b m_{t} J}
$$

Eq. (13) is evaluated separately for the pinion and gear in gear design. It requires the use of two separate curves in the estimate of $\mathrm{J}$ values, one for the pinion and the other for the gear. In AGMA standards, $\mathbf{J}$ is based on the HPSTC, a fact demonstrated by Rameshkumar et al [16] in an FEM study. In the Lewis formula, the Lewis form factor values for the pinion and gear can be estimated from a single curve which makes its use relatively easier than the $\mathrm{J}$ values. Thus it seems attractive for preliminary sizing of gears to explore the option of estimating $\mathbf{J}$ values at HPSTC from a single curve. In pursuance of this option, an attempt was made to estimate the AGMA J values at HPSTC from the AGMA J values for the transmitted load acting at the gear tooth tip and the gear contact ratio during operation. Consequently, the root bending stress may be estimated as:

$$
\sigma_{b}=\frac{2 K_{s} T \times 10^{3}}{d b m_{t} Y}
$$

It must be pointed out that the parameter $Y$ in Eq. (14) does not have the conventional meaning of the "modified Lewis form factor" in gear design. It is used here as an approximation of the AGMA J-factor when one pair of gear teeth is carrying the transmitted force load at the HPSTC
$[24,25]$. In the a previous study [21] it was found that for spur gears, $Y$ may be estimated as:

$$
Y=0.875 J^{\prime} \varpi_{t}
$$

AGMA $J^{\prime}$ values for standard full-depth involute $20^{\circ}$ pressure angle gears may be obtained using the expressions of Eqs. (16a) and (16b).

$$
\begin{aligned}
\text { For } 12 \leq \mathrm{z}<70 \\
\begin{aligned}
J^{\prime}= & -9 z^{4} \times 10^{-9}+2.45 z^{3} \times 10^{-6} \\
& -2.25 z^{2} \times 10^{-4}+9.15 z \times 10^{-3}+0.1308
\end{aligned}
\end{aligned}
$$

For $70 \leq \mathrm{z}<300$

$$
J^{\prime}=-3 z^{2} \times 10^{-8}+9 z \times 10^{-5}+0.285
$$

The contact ratio of a spur gear mesh may be obtained as:

$$
\varpi_{t}=\frac{k_{a}+k_{r}}{\pi \cos \phi}
$$

Where:

$$
k_{a}=0.5\left(\begin{array}{c}
\sqrt{\left(z_{1}+2\right)^{2}-\left(z_{1} \cos \phi\right)^{2}} \\
-z_{1} \sin \phi
\end{array}\right)
$$

and:

$$
k_{r}=0.5\left(\begin{array}{c}
\sqrt{\left(z_{2}+2\right)^{2}-\left(z_{2} \cos \phi\right)^{2}} \\
-z_{2} \sin \phi
\end{array}\right)
$$

In Eqs. (12) and (14), the transmitted torque is used instead of the transmitted force. This is informed by the fact that at the beginning of a gear design problem, the transmitted power and the rotational speed of the input or output shaft may be known or can be estimated. Hence the input or output torque may be estimated. Sometimes the torque and rotational speed at the input or output of a gearbox may be specified altogether. The simplicity of the approach above is that reference to tables in spur gear design during preliminary sizing is largely eliminated except for the external overload factor if it is not given as design specification. It should be noted that the mesh transmission efficiency of a spur gearset has been neglected in the reformulated equations. The power loss per mesh in cylindrical gear drives is of the order of $1 \%$ [7] which is considered negligible above. This loss may be accounted for 
in critical applications by multiplying the torque at the driven gear by the mesh efficiency.

\section{DESIGN SIZING FORMULATION}

The objective in design sizing is to obtain initial estimate of a component size based on specific serviceability criteria. In gear design, contact fatigue (pitting) and bending fatigue failures are the most commonly used serviceability criteria. Pitting failure manifests as wear on the flanks and faces of gears while bending failure manifests as cracks and fractures. Pitting wear is mostly gradual while bending failures are often sudden so pitting wear failure is preferred to tooth breakage. Therefore it is common to ensure that the pitting wear capacity is slightly less than the bending capacity in gear design practice. For design sizing in pitting resistance the contact stress should be at most equal to the allowable Hertz stress. Thus Eq. (12) may be rendered as:

$10^{3} \times\left[\frac{2 K_{f} K_{s}(\mu \pm 1) E_{c} T_{1}}{b d_{1} d_{2}}\right]^{\frac{1}{2}} \leq S_{H}$

where the design parameters and units are $S_{H}(\mathrm{MPa})$, $E_{c}(\mathrm{GPa}), T_{1}(\mathrm{Nm}), b(\mathrm{~mm}), d_{1}(\mathrm{~mm})$, and $d_{2}(\mathrm{~mm}) . K_{f}$, $K_{s}$, and $\mu$ have no units.

Most often the input torque is given in a design problem. Alternatively, the input power and rotational speed of a drive are given or can be evaluated. Then the input torque is obtained as:

$T_{1}=\frac{30 P_{1} \times 10^{3}}{\pi N_{1}}$

The speed or gear ratio is often known or can be estimated at the beginning of gear design. It is at most 7 in general purpose drives but may be up to 10 in special cases. The speed ratio is limited to 4 in change-gearsets [4] and if it is more than 6 , multi-stage transmission should be considered [26].

If the aspect ratio is not specified in a design problem, an estimate needs to be made. Highest values are used for straddle mounted gears with low asymmetric ratio and lowest values for cantilever mounted gears [21]. Assuming low asymmetric ratio straddle mounting, a tentative value of $\lambda_{b}$ may be obtained as:

$\lambda_{b} \approx 0.35+\frac{\mu}{\mu+1}$

The aspect ratio, $\lambda_{b}$ is usually kept below 2.0 to minimize bending and twisting of pinion and a commonly used value is 1.0. No serious effect of bending and twisting of pinion occur for aspect ratio less than 1.15 for straddle mounted gears [25].

In Eq. (19), $K_{o}$ is generally known or may be assumed at the design sizing phase. Now the factors $K_{v}, K_{m}$ and $K_{r}$ are dependent on the gear size in some way. $K_{v}$ depends on the tangential velocity and gear quality while $K_{m}$ is a function of the gear aspect ratio and width. Schmid, Hamrock and Jacobson [26] suggest an approximate value for $K_{m}$. Limiting $\lambda_{b}$ to a minimum value of 0.5 a slightly modified but more conservative form of the approximate value for $K_{m}$ is:

$$
K_{m} \approx 1+\lambda_{b}\left[0.2+0.0112\left(\frac{2 K_{o} T_{1}}{\lambda_{b}}\right)^{1 / 3}\right]
$$

Eq. (22a) clearly shows the dependence of $K_{m}$ on the rated load. Since $K_{v}$ partly depends on the tangential speed which is rated to the gear pitch diameter, it is suggested that:

$K_{v} \approx K_{m}+0.125$

$K_{r}$ depends on gear module and whole depth [7, 12, 21] and may be assumed as 1.0 during initial sizing but should be refined later. The suggested value of $K_{c}$ is 1.1[21]. For design sizing, we can then estimate $K_{s}$ from Eq (11) as:

$$
K_{s} \approx 1.1 K_{o} K_{v} K_{m}
$$

It is emphasized that a new and more accurate estimate of $K_{s}$ is required during design verification and the component parameters should be evaluated based on AGMA [27] recommendations.

Generated spur gears should have at least 17 teeth on a pinion to avoid undercutting of tooth profile [4, 7, 12, 28]. But some experts say a little undercutting in gears does not adversely affect their smooth running and suggest 14 as minimum pinion teeth [4]. In high-speed drives, it is suggested that the minimum pinion teeth should be 26 [28]. For initial sizing in low-speed drives, it is suggested that:

$$
z_{1} \approx 26-1.5 \mu_{o}
$$


And in high-speed drives:

$z_{1} \approx 26+\left(\mu_{o}-1\right)$

Note that higher gear teeth numbers gives slightly higher gear mesh efficiency [4] which may be significant in compound or multi-stage transmission drives. In power drives, the use of a "hunting tooth" is greatly encouraged for even wear distribution among gear teeth.

Now:

$b=\lambda_{b} d_{1}$

$d_{2}=\mu_{o} d_{1}$

$d_{1}=m_{t} z_{1}$

Combining Eqs. (19) and (25):

$m_{t} \geq \frac{100}{z_{1}}\left[\frac{2 K_{f} K_{s}\left(\mu_{o} \pm 1\right) E_{c} T_{1}}{\mu_{o} \lambda_{b} S_{H}^{2}}\right]^{1 / 3}$

Estimation of $S_{H}$ is discussed by AGMA [27]. For power transmission drives, it is recommended that $m_{t} \geq 2 \mathrm{~mm}$ [Petrov, p. 135]. Eq. (26) allows an initial estimate of the module based on contact fatigue strength or pitting resistance.

An initial estimate of the module based on bending fatigue strength can also be developed from Eq. (14). The maximum bending stress should be at most equal to the allowable bending stress. Therefore, Eq. (14) becomes:

$\frac{2 K_{f} K_{s} T_{1} \times 10^{3}}{d_{1} b m_{t} Y} \leq S_{b}$

Substituting Eqs. (25a), (25b), and (25c) in (27); we have:

$m_{t} \geq 10 \times\left[\frac{2 K_{s} T_{1}}{z_{1}^{2} \lambda_{\mathrm{b}} S_{t}}\right]^{1 / 3}$

where:

$S_{t}=\min \left(Y_{1} S_{b 1}, Y_{2} S_{b 2}\right)$

Based on the estimated values of $m_{t}$ from Eqs. (26) and (28), a standard module value should be chosen. The chosen module value should be at least equal to the larger estimated value. However either Eq. (26) or Eq. (28) may be used to estimate a gear module and then a selection of a standard module made. Module size may be changed during design verification. The design sizing task ends with a choice of a standard module.

\section{DESIGN VERIFICATION}

Design verification deals with the assessment of the adequacy of a component or assembly design. It is done to ensure that the selected form and dimensions of a component or assembly meet design requirements. With the gear module established, design verification task can be initiated. The number of gear teeth is estimated as:

$$
z_{2} \approx \mu_{o} z_{1}
$$

An integer value for $z_{2}$ must be chosen. Then refine:

$$
\mu=\frac{z_{2}}{z_{1}}
$$

Choosing a higher module value than estimated allows a designer to reduce $z_{1}$ and $z_{2}$ while keeping $\mu$ constant.

When a hunting tooth is used in power drives, the speed ratio error or tolerance should be checked. That is:

$\epsilon_{o}=\frac{100\left(\mu_{o}-\mu\right)}{\mu_{o}}$

AGMA recommended tolerance $\left(\epsilon_{o}\right)$ on speed ratios are $\pm 3 \%$ for single-stage reduction, $\pm 4 \%$ for double- and triplestage reduction and $\pm 5 \%$ for quadruple-stage reduction.

Once an acceptable $\epsilon_{\mu}$ value is established, estimate gearset basic dimensions:

$$
d_{1}=z_{1} m_{t}
$$

$d_{2}=z_{2} m_{t}$

$b=\lambda_{b} d_{1}$

$b_{2}=b$

$b_{1} \leq b_{2}+5 m m$

$C=0.5\left(d_{1}+d_{2}\right)$ 
Values of $d_{1}, d_{2}, b$, and $C$ can be selected from preferred number series such as R10 or R20 [4, 7, 12, 28].

Determine:

$V_{t}=\frac{\pi d N}{60000}$

Based on $V_{t}$, select a gear quality grade and determine $K_{v}$. AGMA/ISO gear quality numbers range from 0 to 12 , with lower numbers representing higher gear quality. Cast, forged, and pressed gears will roughly be of gear quality numbers 10 to 12 , form cut gears about 9 to 10 , shaped or hobbed gears of 8 to 9 , shaped or hobbed and fine finished gears of 6 to 7, shaped or hobbed and ground gears of 4 to 5 quality numbers [4]. Gears of quality numbers 5 and below are for very accurate gearing. The most popular gear quality numbers are 6 to 9. Quality number values should be selected based on experience. Note that estimates of $K_{v}$ are approximate and tend to be on the conservative side. According to Schmid, Hamrock and Jacobson [26], a $K_{v}$ value of 1.43 is considered conservative, therefore, it is suggested that any estimate of $K_{v}$ above 1.5 should be considered as probably unacceptable. A lower AGMA/ISO gear quality number can be considered to lower its value.

Determine the value of $K_{m}$ more accurately. AGMA has two approaches for estimating the mesh overload factor: analytical and empirical. Analytical method considers the stiffness and masses of individual gears and gear teeth and the total mismatch between mating teeth. Analytical method is rather complicated but should be considered if gear speed is over $20 \mathrm{~m} / \mathrm{s}$. The empirical approach is recommended for normal, relatively stiff gear assemblies, and requires minimum information. It is limited to straddle mounted gears, gear aspect ratio of $\lambda_{b} \leq 2.0$, gear face width, $b \leq$ $1000 \mathrm{~mm}$ (40"), and full mesh contact over face of narrowest gear. Similarly determine $K_{r}$ that depends on gear tooth base support rigidity which is assessed by the rim backup ratio. This ratio is defined as the rim thickness divided by the whole depth of gear tooth. AGMA experimental data suggest that when the rim backup ratio is greater than 1.2, the rim rigidity factor is unity, otherwise it is above unity. A rim back up ratio of 1.2 suggests a rim thickness of about three times the gear module for spur gears.

With $K_{o}, K_{v}, K_{m}, K_{r}$ and $K_{c}$ known, then $K_{s}$ can be determined from Eq. (11). Please refer to AGMA standards and [Osakue, 2016] on how to obtain more accurate values of these parameters. Sometimes, $S_{c}$ and or $S_{F}$ are revaluated due to the gear size factor.
Evaluate the expected contact stress using Eq. (12), and the expected bending stress using Eq. (14). The deviation of the expected contact stress from the allowable value should be assessed as:

$$
\epsilon_{H}=\frac{100\left(S_{c}-\sigma_{H}\right)}{S_{c}}
$$

For proper utilization of material; $15 \% \leq \epsilon_{H} \leq-5 \%$ [28, 29 ]. If this condition is not satisfied consider changing the gear face width. If this does not resolve the problem, consider changing gear pitch diameters and face width.

Over stressing occurs when $\epsilon_{H}<-5 \%$ and should be avoided due failure possibility. Under stressing occurs when $\epsilon_{H}>15 \%$, failure is unlikely but a case of over design may happen and material is wasted. Values of $\epsilon_{H}$ more than $15 \%$ may be appropriate if considerable economic damage or safety is a probable consequence of failure.

It can be shown that the design factor for contact fatigue is:

$$
n_{H}=\frac{1}{1-0.01 \epsilon_{H}}
$$

The design factor for bending fatigue is:

$$
n_{F}=\frac{S_{F}}{\sigma_{H}}
$$

AGMA general approach to gear design uses equations, charts and graphs which are many and sometimes complicated. The AGMA equations incorporate modification factors informed by experimental data and experience. Gear design is complex and experiments are the only means to accurately ascertain the load capability or rating of gearsets [4]. The approach presented above uses no graphs or charts if the external overload factor is specified in a design problem. The equations are in simple forms except perhaps those used for estimating the internal and mesh overload factors.

\section{DESIGN EXAMPLES}

The new design formulas presented in the previous sections are tested in three design examples. The first example is a design verification problem which requires determining the contact stress and root bending stress using the stress capacity models of Eq. (12) and Eq. (14). The other two examples involve design sizing and design verification. The examples are taken from the published works of respected authors and are paraphrased here. The equations presented were coded in Microsoft Excel for computational efficiency. The spreadsheet has two pages of two sections per page. The first page has a material selection and strengths estimation sections. The second page has design sizing and design 
verification sections. Iteration during design verification can be done by changing values of gear module, teeth, effective face width, and pitch diameters.

\subsection{Example 1}

This example is taken from Mott [7, pp. 392 - 401], and paraphrased by the authors. A steel gearset for an industrial saw requiring $18.64 \mathrm{~kW}$ consists of a pinion running at 1750 $\mathrm{rpm}(183.22 \mathrm{rad} / \mathrm{s})$. The gear unit is enclosed, of commercial standards with gears straddle mounted between bearings. The gear blanks are solids and the following data apply: $K_{o}=1.5, z_{1}=20, z_{2}=70, b=38.1 \mathrm{~mm}, m_{t}=3.175 \mathrm{~mm}$, $q_{n}=11$. What are the expected Hertz contact and root bending stresses?

Table 1 summarizes the computational results for design Example 1 from the spreadsheet. The expected contact stress is $1054 \mathrm{MPa}$, the expected pinion root bending stress is 211 $\mathrm{MPa}$, and the expected gear root bending stress is $178 \mathrm{MPa}$.

Table 1: Design Example 1 Results

\begin{tabular}{|l|l|l|l|l|}
\hline Parameter & Value & Parameter & Value & Unit \\
\hline$z_{1}$ & 20 & $V_{t}$ & 3.491 & $\mathrm{~m} / \mathrm{s}$ \\
\hline$z_{2}$ & 70 & $E_{c}$ & 230 & $\mathrm{GPa}$ \\
\hline$\mu$ & 3.5 & $T_{1}$ & 102 & $\mathrm{Nm}$ \\
\hline$K_{o}$ & 1.50 & $T_{2}$ & 356 & $\mathrm{Nm}$ \\
\hline$K_{v}$ & 1.442 & $d_{1}$ & 63.5 & $\mathrm{~mm}$ \\
\hline$K_{m}$ & 1.192 & $d_{2}$ & 222.25 & $\mathrm{~mm}$ \\
\hline$K_{r}$ & 1.00 & $b$ & 38.1 & $\mathrm{~mm}$ \\
\hline$K_{c}$ & 1.10 & $m_{t}$ & 3.175 & $\mathrm{~mm}$ \\
\hline$K_{s}$ & 2.836 & $\sigma_{H}$ & 1054 & $\mathrm{MPa}$ \\
\hline$K_{f}$ & 1.0 & $\sigma_{b 1}$ & 211 & $\mathrm{MPa}$ \\
\hline$q_{n}$ & 11 & $\sigma_{b 2}$ & 178 & $\mathrm{MPa}$ \\
\hline
\end{tabular}

\subsection{Example 2}

Design a $20^{\circ}$ standard pressure angle spur gearset to be used in a drive for a chipper to prepare pulp-wood in a paper mill. Intermittent use is expected and the design life is $3000 \mathrm{hr}$. An electric motor transmits $2.2 \mathrm{~kW}$ to the pinion at 1750 rpm and the gear must rotate between 460 and $465 \mathrm{rpm}$. A $K_{o}=1.75$ is considered suitable and the gears are machined from AISI 4140 steel; that will be quenched and tempered with hardness of $340 \mathrm{HBN}$ [7, p. $410-412]$.

Design sizing estimates yielded pinion teeth number of 20 , gear teeth number of 76 , and module values of $1.46 \mathrm{~mm}$ and $1.37 \mathrm{~mm}$ for pitting wear and bending fatigue resistances, respectively. A standard module value of $2 \mathrm{~mm}$ [7] was chosen, representing about 35\% increase over the larger estimated value. For compact design, the pinion teeth number was reduced to 19 and that the gear to 72 in the first iteration of design verification.
Table 2 summarizes the computational results for design Example 2 from the spreadsheet. The new solution was obtained after three iterations of $b=35 \mathrm{~mm}, b=30 \mathrm{~mm}$ and $b=25 \mathrm{~mm}$. The first iteration yielded a contact stress deviation of $20.53 \%$ and pinion bending stress design factor of 3.13 which were considered too high. So the gear face width was decreased to $30 \mathrm{~mm}$ in the second iteration. The second iteration gave a contact stress deviation of $14.77 \%$ and a pinion bending stress design factor of 2.77. These values are relatively on the high side considering the pinion bending stress design factor. A third iteration with $b=25$ $\mathrm{mm}$ was performed and the contact stress deviation of $7.31 \%$ and pinion bending stress design factor of 2.41 were obtained. Note that the bending stress design factor of the gear was higher in each iteration case. The almost identical solutions in Table 2 are worth noting.

Table 2: Design Example 2 Results

\begin{tabular}{|c|c|c|c|c|}
\hline \multirow{2}{*}{ Parameter } & \multicolumn{2}{|c|}{ Current } & \multicolumn{2}{|l|}{ [7] } \\
\hline & Pinion & Gear & Pinion & Gear \\
\hline$m_{t}(\mathrm{~mm})$ & \multicolumn{2}{|l|}{2} & \multicolumn{2}{|l|}{2.117} \\
\hline$z$ & 19 & 72 & 18 & 68 \\
\hline$d \quad(\mathrm{~mm})$ & 38 & 144 & 38 & 144 \\
\hline$b \quad(\mathrm{~mm})$ & 30 & 25 & 25.4 & 25.4 \\
\hline$C(\mathrm{~mm})$ & \multicolumn{2}{|l|}{91} & \multicolumn{2}{|l|}{91.03} \\
\hline$n_{F}$ & 2.41 & 2.57 & 2.35 & 2.88 \\
\hline$n_{H}$ & \multicolumn{2}{|l|}{1.08} & \multicolumn{2}{|l|}{1.04} \\
\hline
\end{tabular}

\subsection{Example 3}

Design a $20^{\circ}$ standard pressure angle spur gearset to transmit $30 \mathrm{~kW}$ from a pinion running at $960 \mathrm{rpm}$ to a gear running at $320 \mathrm{rpm}$. A design life of $10^{8}$ load cycles is desired. Use $K_{o}=1.25$ and assume steel materials are for gears that will be quenched-tempered with pinion hardness of $475 \mathrm{HBN}$ and gear hardness of $450 \mathrm{HBN}$ [30]. Design sizing estimates yielded pinion teeth number of 21 , gear teeth number of 63 , and module values of $3.31 \mathrm{~mm}$ and $3.36 \mathrm{~mm}$ for pitting wear and bending fatigue resistances, respectively. A standard module value of $3.5 \mathrm{~mm}$ [7] was chosen.

Table 3: Design Example 3 Results

\begin{tabular}{|l|l|l|l|l|}
\hline \multirow{2}{*}{ Parameter } & \multicolumn{3}{|l|}{ Current } & [30] \\
\cline { 2 - 5 } & Pinion & Gear & Pinion & Gear \\
\hline$m_{t}(\mathrm{~mm})$ & \multicolumn{3}{|l}{3.5} & 5.0 \\
\hline$z$ & 22 & 66 & 17 & 51 \\
\hline$d(\mathrm{~mm})$ & 77 & 231 & 85 & 255 \\
\hline$b(\mathrm{~mm})$ & 75 & 70 & 50 & 50 \\
\hline$C(\mathrm{~mm})$ & 154 & & 170 & \\
\hline$n_{F}$ & 1.97 & 1.91 & 1.97 & 2.30 \\
\hline$n_{H}$ & 1.14 & & 1.14 & \\
\hline
\end{tabular}


Table 3 summarizes the computational results for design Example 3 from the spreadsheet. The new solution was obtained after two iterations of $b=65 \mathrm{~mm}$ and $b=70 \mathrm{~mm}$. The first iteration yielded a contact stress deviation of $9 \%$ which was considered inadequate for quenched-tempered steel of hardness $450 \mathrm{HBN}$ and above. So the gear face width was increased to $70 \mathrm{~mm}$ in the second iteration. The new value has a contact stress deviation of $12.4 \%$. The solutions in Table 3 are quite close though the new one gives slightly smaller dimensions.

\section{COMPARISON OF RESULTS}

As indicated previously, the solutions for design Example 2 are practically the same and those of design Example 3 are very close. In design Example 3, the current solution has more gear teeth but smaller module size and the center distance is smaller than the cited solution. Conventional wisdom seems to suggest that minimizing gear teeth also minimizes gear size because most conventional designs assume pinion teeth as 17 or 18 ! Thus conventional wisdom is challenged in this example. The center distance is indicative of gearbox size which influences manufacturing cost. Smaller module sized gears are easier to make. Therefore pinion teeth more than 18 may be used so as to take advantage of size reduction, lower manufacturing cost and achieve higher mesh efficiency.

Table 4: Load Factor Estimates

\begin{tabular}{|l|l|l|l|}
\hline $\begin{array}{l}\text { Load } \\
\text { Factors }\end{array}$ & $\begin{array}{l}\text { Design } \\
\text { sizing }\end{array}$ & $\begin{array}{l}\text { Design } \\
\text { verification }\end{array}$ & $\begin{array}{l}\text { Deviation } \\
(\%)\end{array}$ \\
\hline \multicolumn{4}{|l|}{ Design Example 2} \\
\hline$K_{m}$ & 1.231 & 1.202 & -2.33 \\
\hline$K_{v}$ & 1.356 & 1.353 & -0.22 \\
\hline$K_{s}$ & 3.213 & 3.131 & -2.62 \\
\hline Design Example 3 & & 1.27 \\
\hline$K_{m}$ & 1.242 & 1.258 & -5.32 \\
\hline$K_{v}$ & 1.367 & 1.298 & 3.85 \\
\hline$K_{s}$ & 2.246 & 2.336 & \\
\hline
\end{tabular}

Table 4 compares estimates of mesh overload, internal overload and service load factors for design sizing and design verification tasks of Examples 2 and 3. The values for design sizing are based on Eqs. (22a), (22b), and (23), respectively. The design verification values are based on AGMA empirical methods. The deviation column shows the percentage variance between the two values. The highest variance is $-5.32 \%$, indicating a slightly higher or conservative value for design sizing. Clearly the approximated results compare very favorably with the AGMA values and thus acceptable.

Table 5 compares contact and bending stresses based on the approach presented and that of AGMA. The results display a remarkable closeness in values because the largest error is $5.23 \%$ for contact stress in design Example 2 and $-6.59 \%$ for root bending stress for design Example 1.
Table 5: Results Comparison for Design Examples

\begin{tabular}{|l|l|l|l|}
\hline $\begin{array}{l}\text { Stress } \\
\text { Type }\end{array}$ & $\begin{array}{l}\text { AGMA } \\
(\mathbf{M P a})\end{array}$ & $\begin{array}{l}\text { Current } \\
(\mathbf{M P a})\end{array}$ & $\begin{array}{l}\text { Deviation } \\
(\%)\end{array}$ \\
\hline Design Example 1 \\
\hline$\sigma_{H}$ & 1076 & 1055 & 1.95 \\
\hline$\sigma_{b}$ & $\begin{array}{l}208 \\
167^{*}\end{array}$ & $\begin{array}{l}211 \\
178^{*}\end{array}$ & $\begin{array}{l}-1.44 \\
-6.59^{*}\end{array}$ \\
\hline Design Example 2 \\
\hline$\sigma_{H}$ & 847.4 & 803.1 & 5.23 \\
\hline$\sigma_{b}$ & 117.9 & 115.9 & 1.70 \\
\hline & $91.7^{*}$ & $94.11^{*}$ & $-2.63^{*}$ \\
\hline Design Example 3 \\
\hline \multicolumn{5}{|l|}{$\sigma_{H}$} & 982.5 & 990.3 & 0.79 \\
\hline$*$ Values for root bending stress for gear \\
\hline
\end{tabular}

In Table 4, the estimated service load factor for Example 2 is 3.13 and that for Example 3 is 2.34. These values suggest that the gear teeth in Example 2 could experience over three times the rated load while those in Example 3 could experience almost 2.5 times the rated load on a recurrent basis in operation. Very high values of service load factor should be investigated for possible reduction. Low service load factor values lead to reduction in the size and cost of gear supporting elements like shafts, bearings, housings, etc.

While more examples are perhaps necessary for further verification of the design approach presented, it may be concluded from these results that the approach used appears to be an acceptable one in preliminary design of spur gears.

\section{CONCLUSION}

New perspectives such as harmonic mean, translating third body concept of the contact patch, contact form factor, and service load factor are introduced in spur gear design. The contact patch has its own geometric and physical properties based on the harmonic mean rule. The contact form factor may be used to assess the relative load capacities of different gear pressure angle standards. The service load factor captures the influence of different conventional rated load modifier factors. It has a multiplicative model that incorporates factors such as external and internal overload factors, mesh overload factor, etc. into a single factor that directly shows the magnification of the rated design load for an application.

The Hertz contact stress and Lewis root bending stress for design verification for spur gears have been reformulated and simplified. The expression provided for the Hertz contact stress clearly relates the significant design parameters explicitly for spur gear. Design sizing formulas are formulated and estimates of gear module can be made based on pitting and bending fatigue resistances. The approach uses minimum design data input of rated torque, input or output speed and speed ratio, or rated power, input and output speeds, and design life. The gearset materials may be specified in design statement(s) but it is not required since the designer can make his or her own choice about the gearset materials and hardness. 
From the three design Examples considered, it is demonstrated that the contact and root bending stress results obtained by this approach compare very favorably with AGMA results. Similarly, the approximations for the mesh overload, internal overload, and service load for design sizing match closely with the respective values obtained during design verification using AGMA approach. Consequently, the design approach appears to be an acceptable one in the preliminary design of spur gears.

\section{ACKNOWLEDGEMENT}

The authors gratefully acknowledge that this study was supported in parts with funds from COSET Research Fund and the University Faculty Development Fund of Texas Southern University, Houston, Texas.

\section{REFERENCES}

[1] Spur Gear Design, http://www.learnengineering.org/2013/02/spur-geardesign.html (Accessed 2-3-16)

[2] Spur Gear Terms and Concepts, http://www.gearseds.com/files/6.3.1_Gear_Terms_Le sson_rev3.pdf (Accessed 2-3-16)

[3] Collins, J. A., Busby, H., Staab, G. H., (2010), Mechanical Design of Machine Elements and Machines: A Failure Prevention Perspective, $2^{\text {nd }}$ ed., John Wiley and Sons, New York.

[4] Maitra, G. M., (2013), Fundamentals of Toothed Gearing: Handbook of Gear Design, $2^{\text {nd }}$ ed., McGraw Hill, New Delhi.

[5] Kawalec, A, Wiktor, J, \& Ceglarek, D., (2006), Comparative Analysis of Tooth-Root Strength Using ISO and AGMA Standards in Spur and Helical Gears with FEM-bases Verification, Journal of Mechanical Design, Vol. 128, pp. 1141 - 1158.

[6] Euro Trans, (2007), Equivalence between ISO Standards and National Standards Concerning Gear Technology, http://www.euro-trans.org/

[7] Mott, R. L. (2004), Machine Elements in Mechanical Design, $4^{\text {th }}$ ed. SI, Pearson Prentice Hall, New York.

[8] Fernandes, P. J. L. (1996), Tooth Bending Fatigue Failures in Gears, Engineering Failure Analysis, Vol. 3, N0. 3, pp. 219 - 225.

[9] Townsend, D., P., (1986), Common Problems and Pitfalls in Gear Design, NASA Technical Memorandum 88858, http://ntrs.nasa.gov/archive/nasa/casi.ntrs.nasa.gov/19 870007600.pdf (Accessed 2-3-16).

[10] Bergseth, E. (2009), Influence of Gear Surface Roughness, Lubricant Viscosity and Quality Level on ISO 6336 Calculation of Surface Durability, Technical Report, Department of Machine Design, Royal Institute of Technology, Stockholm, https://www.divaportal.org/smash/get/diva2:489751/FULLTEXT01.pd f

[11] Schmid, S. R., Hamrock, B. J. \& Jacobson,B. O., (2014), Fundamentals of Machine Elements, $3^{\text {rd }}$ ed., CRC Press, New York.
[12] Budynas, R. G. \& Nissbett, J. K., Shigley's Mechanical Engineering Design, $9^{\text {th }}$ ed., McGraw Hill Education.

[13] Savage, M. \& Mackulin, M. J. (1991), Maximum Life Spur Gear Design, NASA Technical Memorandum 104361.

http://www.dtic.mil/dtic/tr/fulltext/u2/a237143.pdf

[14] Mechanical Design Data Manual, Chap. 8, Spur and helical gears, http://www.learneasy.info/MDME/modules/7758D_

Machine_Design/gears/gears.pdf. (Accessed 1-10-16)

[15] Bommisetty, V. S. N. K, (2012), Finite Element Analysis of Spur Gear Set, Masters' Thesis, Mechanical engineering Department, Cleveland State University.

[16] Rameshkumar, M., Venkatesan, G. and Sivakumar, P. (2010), Finite Element Analysis of High Contact Ratio Gear, AGMA Technical Paper, https://www.agma.org/assets/uploads/publications/10 FTM06_Rameshkumar.pdf (Accessed 3-8-16)

[17] Pasta, A. Mariotti G. V. (2007), Finite Element Analysis of a Spur Gear with Corrected Profile, The Journal of Strain Analysis for Engineering Design, Vol. 42.

[18] Karaveer, V., Mogrekar, A., and Joseph, T. P. R. (2013), Modeling and Finite Element Analysis of Spur Gear, International Journal of Current Engineering and Technology, Vol. 3, No. 5, pp. 2104 $-2107$.

[19] McVittie, D., (1998), Calculating Spur and Helical Gear Capacity with ISO 6336, Gear Technology, pp. $11-14$.

[20] Walton, D., Shi, Y., \& Taylor, S. (1990), AGMA, ISO, and BS Gear Standards: Part 1-Pitting Resistance Ratings, Gear Technology, pp. 10 - 17.

[21] Osakue, E. E. (2016), Simplified Spur Gear Design, ASME International Conference on Mechanical Engineering, Phoenix Arizona. In Print

[22] Peterson, R. E., (1974), Stress Concentration Factors, John Wiley, New York, pp. 270 - 271.

[23] ASM Metals Handbook, (1975), Failures of Gears, Failure Analysis and Prevention ( $\left.8^{\text {th }} \mathrm{ed},\right)$, Vol. 10, pp. $507-524$.

[24] Norton, R. L. (2000), Machine Design: An Integrated Approach, Prentice-Hall, Upper Saddle River, New Jersey.

[25] Dudley, D. W. (2009), Handbook of Practical Gear Design, CRC Press, Baca Raton.

[26] Schmid, S., Hamrock, B. J., \& Jacobson, B. O., (2014), Fundamentals of Machine Elements, $3^{\text {rd }}$. ed. CRC Press, Boca Raton.

[27] AGMA 2001-D04; http://wp.kntu.ac.ir/asgari/AGMA\%202001-D04.pdf

[28] Petrov, M., Chernilevsky, D., Berezovsky, Y. (1988), Machine Design, MIR, Moscow.

[29] Chernilevsky, D, (1990), A Practical Course in Machine Design, MIR, Moscow.

[30] Gopinath, K. \& Mayuram, M. M., Module 2 Gears, Lecture 10, Spur Gear Design http://nptel.ac.in/courses/112106137/pdf/2_10.pdf 


\section{NOMECLATURE}

HBN = Hardness: Brinnel Number

HPSTC $=$ Highest Point of Single Tooth Contact

$C=$ center distance $(\mathrm{mm})$

$F_{c}=$ contact normal force $(\mathrm{N})$

$b=$ effective gear width (mm)

$E_{1}=$ elastic modulus of pinion $(\mathrm{GPa})$

$E_{2}=$ elastic modulus of gear $(\mathrm{GPa})$

$E_{c}=$ composite contact elastic modulus $(\mathrm{GPa})$

$F_{t}=$ rated transmitted or transverse force $(\mathrm{N})$

$d_{1}=$ pitch circle diameter of pinion $(\mathrm{mm})$

$d_{2}=$ pitch circle diameter of gear $(\mathrm{mm})$

$T_{1}=$ rated torque at pinion $(\mathrm{Nm})$

$T_{2}=$ rated torque at gear $(\mathrm{Nm})$

$N_{1}=$ rotational speed of pinion $(\mathrm{rpm})$

$N_{2}=$ speed of gear (rpm)

$P_{1}=$ power at pinion $(\mathrm{W})$

$m_{t}=$ transverse module of gear $(\mathrm{mm})$

$J=$ AGMA geometric stress factor at HPSTC

$J^{\prime}=$ AGMA $J$-factor for load at gear tooth tip

$Y=$ estimate of AGMA $\mathrm{J}$ factor at HPSTC

$S_{H}=$ allowable contact fatigue stress (MPa)

$S_{b}=$ allowable bending fatigue stress ( $\left.\mathrm{MPa}\right)$

$S_{t}=$ Lewis-AGMA factored stress (MPa)

$z=$ number of teeth on pinion or gear

$k_{a}=$ approach path factor

$k_{r}=$ recess path factor

$z_{1}=$ number of teeth on pinion

$z_{2}=$ number of teeth on gear

$K_{f}=$ gear form factor

$K_{s}=$ service load factor

$K_{o}=$ external overload factor

$K_{v}=$ internal overload factor

$K_{m}=$ mesh overload factor

$K_{r}=$ rim rigidity factor

$K_{c}=$ contact quality factor

$V_{t}=$ tangential pitch point velocity $(\mathrm{m} / \mathrm{s})$

$q_{n}=$ gear quality number

$v_{1}=$ Poisson's ratio of pinion

$v_{2}=$ Poisson's ratio of gear

$\rho_{1}=$ radius of curvature of pinion at pitch point $(\mathrm{mm})$

$\rho_{2}=$ radius of curvature of gear at pitch point (mm)

$\rho_{c}=$ composite radius of curvature at pitch point (mm)

$\phi=$ pressure angle (deg.)

$\mu=$ speed ratio

$\varpi_{t}=$ transverse plane contact ratio

$\sigma_{b}=$ maximum gear root bending stress (MPa)

$\sigma_{H}=$ maximum Hertz contact stress (MPa)

$\epsilon_{H}=$ Hertz contact stress deviation

$\epsilon_{o}=$ speed ratio deviation

$\lambda_{b}=$ gear aspect ratio or face width factor

$1=$ subscript for pinion

$2=$ subscript for gear 